\title{
Qualidade e segurança de vegetais minimamente processados: proposta de estruturas de governança entre os agentes da cadeia e os sinais da qualidade
}

\author{
Quality and safety of minimally processed vegetables: a proposal of \\ governance structures between chain actors and quality signs
}

\author{
André Luis Bonnet Alvarenga ${ }^{1}$ \\ José Carlos de Toledo² \\ Luiz Fernando de Oriani e Paulillo²
}

\begin{abstract}
Resumo: A adequada gestão da qualidade e da segurança dos alimentos é essencial para o alcance de vantagens competitivas para as empresas de processamento mínimo de vegetais. Para essa gestão, são necessários controles preventivos, específicos e sistemáticos durante as etapas de produção dos alimentos para que os produtos atinjam os atributos desejados de qualidade. A cadeia de vegetais minimamente processados (VMP) é composta de produtores rurais, empresa processadora, transportadores de produtos finais e empresas varejistas e mercado institucional. Nesta cadeia, as transações entre seus agentes, apesar da alta frequência, são caracterizadas por grande assimetria de informações e diferenças nas especificidades dos ativos destes agentes, promovendo a possibilidade de ações oportunistas entre eles, principalmente nas relações entre produtores rurais e empresa processadora. Isto gera impactos negativos para a qualidade e a segurança do produto final e, como consequência, pode promover a seleção adversa pelo mercado consumidor e risco moral para as empresas processadoras. O objetivo deste trabalho foi definir e propor as estruturas de governança, entre os agentes desta cadeia, que minimizem os impactos negativos para a qualidade e segurança dos VMP, a partir da análise das especificidades do ativo entre estes agentes e dos atributos das transações. Adotou-se como método de pesquisa o estudo de casos múltiplos compreendendo 18 unidades de análise em duas cadeias de VMP localizadas nos estados de São Paulo e do Rio de Janeiro. Verificou-se que a empresa processadora lidera as transações entre os agentes em função da alta especificidade do seu ativo, em detrimento dos demais agentes. Propõem-se as estruturas de governança híbrida e hierárquica entre esses agentes, cujas formas de contratação dependem do agente e do tipo de matéria-prima transacionado.
\end{abstract}

Palavras-chave: Qualidade e segurança de alimentos. Vegetais minimamente processados. Estruturas de governança. Custos de transação.

\begin{abstract}
Proper management of quality and food safety is essential for minimally processed vegetables industries in order to achieve competitive advantages. Preventive, proactive, systematic, and specific controls during the production steps of food products are needed to reach the desired quality attributes. The minimally processed vegetables (MPV) chain is composed primarily of farmers, a processing plant, final product carriers, retailers, and institutional markets. In this chain, the transactions between these agents, despite the high frequency, are characterized by large information asymmetry and differences in their asset specificity, allowing the possibility of opportunistic behavior among them, especially in the relationship between the farmers and the processing plant. This causes negative effects on the quality and safety of the final product and, consequently, it can result in adverse selection in the consumer market and lead processing plants to moral hazard. The objective of this study was to define and propose governance structures between the actors of this chain that can minimize the negative effects on the quality and safety of such products. A multiple case study comprising of 18 units and two MPV chains in the states of Sao Paulo and Rio de Janeiro was conducted. It was found that the processing plant leads the transactions between the agents due to the high specificity of its assets, to the detriment of other agents. Therefore, hierarchical and hybrid governance structures were proposed based on the contracting agent and type of raw material being transacted.
\end{abstract}

Keywords: Food quality and safety. Minimally processed vegetables. Governance structures. Transaction costs.

\footnotetext{
Embrapa Agroindústria de Alimentos, Av. das Américas, 29501, Guaratiba, CEP 23020-470, Rio de Janeiro, RJ, Brasil, e-mail: andre.bonnet@embrapa.br

2 Programa de Pós-graduação em Engenharia de Produção - PPGEP, Departamento de Engenharia de Produção - DEP, Universidade Federal de São Carlos - UFSCar, Rod. Washington Luís, Km 235, SP-310, CEP 13565-905, São Carlos, SP, Brasil e-mail: toledo@dep.ufscar.br,dlfp@power.ufscar.br
}

Recebido em 22/9/2012 — Aceito em 12/7/2013

Suporte financeiro: Embrapa. 


\section{Introdução}

A adequada gestão da qualidade e seus elementos são essenciais para o alcance de vantagens competitivas para as empresas. Para a indústria de alimentos, o cenário não é diferente e, de fato, apresenta-se particularmente complexo. $\mathrm{O}$ alimento é matriz complexa e heterogênea, cuja qualidade final é difícil de ser mensurada apenas por meio de ensaios que, além de destrutivos, onerosos e demorados, frequentemente requerem planos amostrais não triviais. Tais limitações impedem o emprego isolado de controles do tipo amostragem-análise em sistemas de garantia da qualidade de alimentos.

O processamento mínimo de vegetais (frutas, legumes e verduras) (PMV) é uma tecnologia estabelecida nos EUA em meados da década de 1970 e que chegou ao Brasil no início da década de 1990, buscando atender ao novo perfil de demanda dos consumidores. O objetivo principal do PMV é torná-los práticos e convenientes para consumo pelo consumidor final, com o máximo período de vida útil e com o frescor e valores nutricionais muito próximos ao produto in natura que o origina. A sua apresentação é de vegetais já higienizados (prontos para o consumo) idênticos ao in natura, embalados em filmes ou embalagens rígidas poliméricas (sacos ou bandejas, respectivamente) e conhecidos como vegetais minimamente processados (VMP).

Para garantir a qualidade e a segurança no consumo dos VMP, as trocas entre os agentes desta cadeia têm que ser iniciadas, negociadas e completadas, exigindo informações que são desigualmente distribuídas entre estes, cuja capacidade humana é limitada em processá-las, e que têm um custo elevado para serem adquiridas, mantidas e acessadas. Torna-se fundamental a integração entre estes agentes para tornar eficiente o resultado final das transações. Essa eficiência é alcançada com transparência nas suas transações (fluxo de informações efetivas e eficientes), o que leva ao alicerçamento de suas relações de colaboração mútua e parcerias de longo prazo. Esta eficiência é alcançada com estruturas de governança bem definidas entre os agentes, pois minimizam a possibilidade de ações oportunistas nas transações, tendo como impacto global a redução dos custos de transação. Nantes e Leonelli (2003) observaram que o segmento de VMP como um todo revela-se ineficiente devido à forma desestruturada em que se encontram os diversos agentes desta cadeia produtiva. Esta observação é confirmada por outros estudos focando os agentes das cadeias agroindustriais de processamento de batatas e de fécula de mandioca e na produção de hortaliças (CORDEIRO; TREDEZINI; CARVALHO, 2008; VILPOUX, 2011; STRYDOM et al., 2012).

Este artigo tem por objetivo identificar as barreiras transacionais e de gestão em cadeias de VMP que podem levar a problemas de qualidade e segurança nos produtos finais e identificar as estruturas de governança entre os agentes da cadeia que minimizem as barreiras transacionais entre eles. Para isto, o método de pesquisa empregado para este estudo exploratório foi o estudo multicasos (YIN, 2007). O estudo foi realizado em duas cadeias de processamento mínimo de vegetais, compreendendo, cada uma, uma empresa processadora, três produtores rurais, duas empresas transportadoras $\mathrm{e}$ três empresas distribuidoras, totalizando nove unidades de análise para cada cadeia e dezoito no total. O artigo é estruturado em um referencial teórico, abordando como os principais elementos da teoria dos custos de transação influenciam na qualidade dos produtos finais, na discussão dos resultados observados do estudo exploratório e na proposta das estruturas de governança para a cadeia de VMP.

\section{Referencial teórico}

\subsection{Contribuições da Teoria dos Custos de Transação à Gestão da Qualidade}

O conceito de custos de transação foi ampliado a partir de sua introdução por Coase (1937), considerando os custos para planejar, adaptar e monitorar as relações entre os agentes de uma determinada cadeia, garantindo o cumprimento dos termos contratuais, uma vez que as informações são distribuídas assimetricamante entre as partes da transação e por dois pressupostos básicos: a possibilidade de ações oportunistas e a racionalidade limitada entre as partes que transacionam (WILLIAMSON, 1985). As ações oportunistas podem acontecer como consequência de um forte autointeresse das partes, podendo, se houver interesse, mentir, trapacear ou quebrar promessas, pois são derivadas da incerteza e levam à falta de previsibilidade e à falta de cooperação; a racionalidade limitada deriva da incompletude contratual, ou seja, devido aos limites cognitivos dos indivíduos, não existe a possibilidade de se estabelecer contratos que prevejam todos os acontecimentos futuros, gerando contratos intrinsecamente incompletos e elevando os custos de transação (AZEVEDO, 2000; MALLMANN, 2000).

De acordo com Zylberzstajn e Farina (1999), para atingir um nível adequado de coordenação em cadeias de suprimentos é necessário compreender profundamente a natureza das transações entre os agentes em toda a cadeia. Assim, a contribuição deste item é a identificação dos elementos que afetam as transações entre os agentes e que, consequentemente, podem afetar a qualidade e a segurança dos produtos finais da cadeia de processamento mínimo de vegetais.

Machado (2002) reuniu várias definições de custos de transação, que se complementam entre diversos autores na literatura, que podem ser sintetizadas e interligadas para defini-los como os custos necessários para movimentar o mecanismo econômico e social, 
distintos dos custos de produção, que surgem à medida que os agentes se relacionam para trocarem direitos de propriedade entre si, por meio de elaboração e negociação de contratos, da mensuração e fiscalização desses direitos, do monitoramento, desempenho e organização de atividades, incluindo os custos relacionados à ineficiência de adptação das partes diante das mudanças no ambiente econômico.

A partir desta definição, atividades relacionadas à gestão de qualidade, tais como a definição contratual dos requisitos da qualidade de matéria-prima, insumos e produtos finais, o monitoramento destes requisitos, a documentação necessária, a formação e análise de indicadores de desempenho e processos relacionados à melhoria contínua, estão relacionadas a custos de transação.

Seguindo a lógica da definição dos custos de transação, Azevedo (2000) estabelece que quanto mais apropriada for a coordenação entre as partes que transacionam, menores serão os custos de cada uma delas, mais rápida será a adaptação às mudanças de ambientes e menos custosos serão os conflitos inerentes às relações entre clientes e fornecedores. Ainda, segundo este autor, as partes que transacionam usam mecanismos apropriados para regular uma determinada transação, denominados estruturas de governança, com o objetivo de reduzir os custos de transação.

Sproesser, Rosina e Vilpoux (2010) complementam a Teoria dos Custos de Transação (TCT) com a Teoria Econômica das Convencções (TEC) em uma análise interessante para os sistemas agroindustriais, em que o ambiente institucional é regido por normas de comportamento, pelas convenções, pelos códigos de condutas e pelo que estes autores chamam de mundos, que são ambientes particulares com valores distintos e que dão origem a regras comportamentais diferentes entre si, que influenciam na forma de coordenação das estruturas. Para a TEC, estes autores definem a confiança e a reputação como características básicas de transações e a boa fé e idoneidade como pressupostos comportamentais. A análise complementar da TEC com a TCT resulta em uma análise detalhada das estruturas de governança propostas por Williamson (1985), que se desdobram em outras quatro estruturas adicionais (mercado com garantias informais, contratos com garantias fracas, contrato com garantias médias, contrato com garantias fortes-quase integração vertical). A proposta dos autores desdobra a estrutura híbrida de coordenação como um escalonamento entre as estrutras de mercado e de integração vertical, de acordo com os pressupostos comportamentais e as características básicas das transações estabelecidas para a TEC. Para os objetivos desta pesquisa, o resultado da análise da TCT é suficiente.

Voltando à lógica da TCT, e mesmo da TEC, para a gestão da qualidade, as não conformidades existentes em matérias-primas, insumos e produtos finais geram o descarte ou reprocessamento destes materiais (retrabalho), necessidade de treinamento de pessoal, diminuição da produtividade, não atendimento a pedidos e prazos, entre outras. Estas consequências implicam maior ou menor custo e estão diretamente ligadas à menor ou maior coordenação entre os agentes da cadeia, respectivamente.

\subsection{Atributos de transação}

Williamson (1985) identifica três atributos que interferem em maior ou menor custo de transação e que ditam a estrutura de governança de transações entre firmas, de acordo com as características das transações diante desses atributos: a especificidade do ativo, a incerteza e a frequência.

A especificidade do ativo refere-se a quão específico é um bem e quão custosa é a sua realocação para outro uso. Quanto mais específico for um ativo, maior o custo de transação e maior a probabilidade de ocorrer uma ação oportunista. Os ativos específicos são aqueles que não podem ser re-empregados sem perda de valor, que depende da continuidade da transação na qual ele é específico, gerando uma quase renda, definida como a diferença entre o retorno de uma ativo empregado em uma transação específica e seu retorno em outro emprego alternativo (FARINA et al., 1997; NEVES, 1999). Assim, quanto maior esta diferença, mais específico é o ativo. A literatura descreve seis tipos de especificidade do ativo (MACHADO, 2002; PITELLI, 2004).

Breitenbach (2008) resume que a formação de estruturas de gestão (governança) apropriadas é influenciada por meio de leis, regulamentações, regras de conduta, hábitos culturais, e a assimetria de poder entre os agentes, entre outros, que levam à diminuição da incerteza entre os agentes, a limitação de termos da negociação e a construção de confiança entre as partes, tendo como consequência a diminuição dos custos de transação. Ainda segundo esta autora, a análise dos pressupostos comportamentais e dos atributos de transação levará à melhor estrutura de governança para a cadeia que são as relações de compra e venda simples (mercado), estruturas internas às firmas (hierárquicas) e formas mistas (híbridas) que constituem exemplos de estrutura de gestão distintas.

De acordo com Williamson (1996), na estrutura de governança de mercado não existem relações de dependência entre compradores e vendedores, estando cada um destes livre para novas transações, sem que isto afete a outra parte; na estrutura de governança hierárquica existe a especificidade dos ativos, podendo haver perdas econômicas no reposicionamento do produto no mercado, em meio à incerteza e aos pressupostos comportamentais das partes (oportunismo e racionalidade limitada), sendo necessária uma 
coordenação e monitoramento destas partes envolvidas. $\mathrm{Na}$ estrutura de governança híbrida, as partes são autônomas, porém são dependentes. Powell (1990) resume que a estrutura de governança por hierarquia é adequada para transações que envolvem incerteza, ocorrem com frequência e requerem investimentos específicos para as transações. As estruturas por mercado são adequadas para trocas simples, não repetitivas e não requerem investimentos específicos.

Pitelli (2004) relaciona, baseado em Williamson (1989), os pressupostos comportamentais dos agentes e a especificidade dos ativos na contratação das atividades relacionadas às transações necessárias conforme apresentados no Quadro 1. A ausência da racionalidade limitada leva à teoria econômia clássica em que todas as partes envolvidas têm todas as informações para as escolhas nas transações. Por outro lado, a ausência do oportunismo, leva a relações de confiança entre as partes. A ausência de especificidade dos ativos faz com que o ativo seja facilmente realocado para outros usos, em caso de necessidade, sem quaisquer perdas de valor. A existência de todos os pressupostos comportamentais e especificidade dos ativos em uma transação torna-a custosa, e todo processo de contratação leva à incompletude dos contratos, constituindo um ambiente de alta incerteza, o que confere uma forte tendência para ocorrer ações oportunistas e, nestes casos, a verticalização das transações torna-se menos custosa e de menos riscos para as firmas.

A frequência é outro atributo de transação que indica a quantidade de vezes que determinadas transações ocorrem entre os agentes, sendo uma medida da recorrência de transação. Uma alta frequência de transação leva à formação de uma relação de confiança mútua entre os agentes nas transações e à uma diluição nos custos na adoção de mecanismos complexos, minimizando as ações oportunistas, o que leva à diminuição dos custos de transação (LUCCI; SCARE, 2004; MACHADO, 2002; NEVES, 1999; PITELLI, 2004). Segundo Azevedo, citado por Leme (2007), a maior parte das transações é recorrente, o que possibilita que as partes adquiram conhecimento uma das outras, reduzindo a incerteza, e com a construção de uma reputação em torno da marca, formando um ativo específico e a criação de um compromisso contínuo entre as partes em torno do objetivo comum de continuidade da relação.

Ainda em realção aos atributos de transação, a incerteza refere-se à imprevisibilidade do futuro, à falta de transparência no mercado, à assimetria das informações, que também podem ser incompletas, do risco de não serem cumpridos os termos previstos, e de não se efetivarem as ações esperadas, o que introduz margem para negociações e aumento da probabilidade de ações oportunistas. Este atributo está, ainda, fortemente associado à racionalidade ilimitada, gerando contratos incompletos (AZEVEDO, 2000; LUCCI; SCARE, 2004; MACHADO, 2002; NEVES, 1999).

A relação dos atributos de transação especificidade dos ativos e incerteza podem fornecer uma definição da melhor forma de estrutura de governança conforme o Quadro 2.

\subsection{Elementos de pré e pós-transação e os sinais da qualidade}

Segundo Machado (2002), em um ambiente de incerteza, os agentes não conseguem prever os acontecimentos futuros, aumentando o espaço para renegociação e consequentemente, ampliando as possibilidades para perdas derivadas de comportamento oportunista das partes. A incerteza é causada pela

Quadro 1. Atributos do processo de contratação.

\begin{tabular}{|c|c|c|c|}
\hline \multicolumn{2}{|c|}{ Pressupostos comportamentais } & $\begin{array}{c}\text { Especificidade } \\
\text { dos ativos }\end{array}$ & Formas de contratação \\
\hline Rac. Limitada & Oportunismo & + & Planejamento prevendo todos os problemas \\
\hline 0 & + & + & Promessa baseada em confiança e histórico das transações \\
\hline+ & 0 & 0 & Transações com o mercado \\
\hline+ & + & + & Relações hierárquicas \\
\hline+ & + & &
\end{tabular}

Fonte: Adaptado pelos autores a partir de Williamson (1989).

Quadro 2. Alinhamento dos contratos: especificidade dos ativos e incerteza.

\begin{tabular}{|c|c|c|c|}
\hline \multirow{2}{*}{$\begin{array}{c}\text { Especificidade } \\
\text { dos ativos }\end{array}$} & Baixa & Média & Alta \\
\cline { 2 - 4 } & Mercado & Mercado & Mercado \\
\hline Média & Híbrido & Híbrido/hierárquica & Híbrido/hierárquica \\
\hline Alta & Híbrido & Híbrido/hierárquica & Hierárquica \\
\hline
\end{tabular}

Fonte: Zylbersztajn (1995). 
assimetria de informações entre os agentes nas transações, fruto de sua racionalidade limitada. Neste sentido, Coase (1937) já mostrava que o caminho para as transações entre as firmas era estar estabelecida sob uma estrutura de governança por contratos para minimizar os efeitos da incerteza e, consequentemente, diminuir os custos de transação. Barzel (1997) complementa que as transações envolvendo ativos compreendem a transferência dos direitos de propriedade destes ativos. Ainda, segundo este autor, estes ativos são formados por vários atributos e que devem ser garantidos, evidenciando a complexidade do monitoramento de todas as informações, em função da quantidade de atributos e da assimetria de informações entre os agentes que transacionam. Neves (1999) mostra que as principais estratégias para minimizar os efeitos da assimetria de informações são aumentar o monitoramento e oferecer incentivos econômicos para estimular comportamentos esperados em condições de simetria de informações. Costa e Bialoskorski Neto (2005) classificam a assimetria de informações como seleção adversa e risco moral, que ocorrem, respectivamente, na pré-transação e na pós-transação.

Os sistemas de gestão da qualidade tem por objetivo estabelecer uma integração de atividades e processos no sentido de alcançar os requisitos da qualidade do produto final estabelecidos por um ou mais agentes. A verificação e monitoramento destas atividades resultam em um documento (certificado, relatório de auditoria, entre outros) que evidencia que o produto ou o serviço é adequado ao uso a que se destina. Esta evidência é um sinal da qualidade. Sob o ponto de vista transacional, Barzel (2004) define o sinal da qualidade como a padronização das informações e do produto que contribuem para a diminuição dos custos de transação, já que o comprador fica dispensado da verificação e do monitoramento dos atributos desejados do produto.

O risco moral foi preliminarmente estabelecido por Arrow (1963) e surge em decorrência de uma ação oportunista de uma das partes, sobre um contrato pré-estabelecido, no qual há falta de cumprimento real de cláusulas contratuais por esta parte, motivado pela incapacidade da avaliação e observação de suas ações pela outra parte. Estas partes são definidas, por Jensen e Meckling (1976), como agente e principal, respectivamente. Esta incapacidade de avaliação e observação motiva a ação oculta que é definida por Azevedo (2000) como a incapacidade do Principal observar a ação do Agente, o que leva ao risco moral.

De acordo com Machado (2002), os problemas gerados pela assimetria de informação são associados ao comportamento de natureza ética, afetando diretamente as relações entre os agentes. Para o autor, se os agentes econômicos tivessem uma orientação benigna, não oportunista, os custos de transação não seriam relevantes. Mostra, ainda, que as transações de bens com diferentes qualidades nas quais o vendedor não possui meios para convencer o comprador a respeito da qualidade do produto comercializado tendem a ser ineficientes, na medida em que o fenômeno de seleção adversa elimina as transações dos produtos de boa qualidade.

Para resolver o problema de seleção adversa, o vendedor de produtos de alta qualidade precisa mostrar sinais da qualidade de seu produto em detrimento de seus concorrentes que, pressupostamente, não têm a mesma qualidade. Por outro lado, para evitar o risco moral, os compradores precisam oferecer incentivos aos vendedores para que estes se sintam estimulados a produzirem produtos com a qualidade desejada pelos compradores.

De acordo com Peri e Gaetta apud Machado (2000), os elementos fundamentais que definem a identidade e a função de comunicação do sinal de qualidade de um produto são: um sinal de qualidade é rapidamente identificável e reconhecido.

Alguns estudos caracterizam e analisam as transações e as estruturas de governança existentes em cadeias agroindustriais sob o enfoque dos custos de transação em relação à mão de obra (NUINTIN; CURI; SANTOD, 2012), em relação às negociações de produtores rurais (CORDEIRO; TREDEZINI; CARVALHO, 2008), em relação à análise contratual entre agentes (VILPOUX, 2011). Entretanto, nenhum deles analisa estas transações sob o enfoque da qualidade do produto e nem analisa e pondera os atributos de transação nas relações entre agentes na cadeia agroindustrial do processamento mínimo de vegetais de forma a resultar em transações mais eficientes para garantir e evidenciar um produto final da cadeia com a qualidade esperada. Esta lacuna justifica a condução desta pesquisa.

\section{Método de pesquisa}

O método de pesquisa empregado para este estudo exploratório foi o estudo multicasos (YIN, 2007). A pesquisa foi realizada em duas cadeias de processamento mínimo de vegetais, compreendendo, cada uma, uma empresa processadora, três produtores rurais, duas empresas transportadoras e três empresas distribuidoras, totalizando nove unidades de análise para cada cadeia e dezoito no total. Foram realizadas cinco visitas em cada uma das empresas processadoras e uma visita em cada um dos outros agentes, no período de novembro de 2009 a dezembro de 2010, para entrevistar os agentes selecionados das cadeias, coletar documentos e analisar as atividades de produção e as transações entre os agentes das cadeias. As duas empresas de processamento mínimo de vegetais estão localizadas nos cinturões verdes dos estados de São Paulo (município de Mogi das Cruzes) e do Rio de Janeiro (município de Teresópolis). Cada cadeia foi 
definida e focada neste pesquisa por quatro agentes, a saber: produtores rurais (fornecedores); empresas processadoras (processadores); transportadores e distribuidores que são empresas relacionadas ao mercado varejista (supermercados) e ao mercado institucional (restaurantes e redes de fast food).

\section{Transações entre os atores da cadeia de VMP}

\subsection{A relação produtor rural - processador}

A relação entre produtores rurais e os processadores nos casos estudados é caracterizada por uma alta frequência nas transações. Faulin e Azevedo (2003) afirmam que as especificidades temporais do ativo nas negociações envolvendo produtos perecíveis, como é o caso das hortaliças, é relevante. Esta questão justifica a alta frequência para as transações observadas. $\mathrm{O}$ dia a dia nestas transações faz com que a empresa processadora selecione seus fornecedores de acordo com as expectativas mútuas de cada parte. Assim, elas se adaptam entre si, procurando entender as necessidades de cada uma e construindo uma relação de confiança por meio do cumprimento das obrigações individuais, regidas, em todos os casos estudados, por acordos informais. Como consequência desta adaptação, procuram estabelecer e manter relações de longo prazo.

Os problemas encontrados nas transações entre as partes podem ser resultado direto da falta de compartilhamento de objetivos em comum entre elas nas transações com a matéria-prima. A maior parte dos produtores entrevistados tem como principal objetivo ganhar dinheiro com a venda de seus produtos; o principal objetivo das empresas processadoras é obter matéria-prima com qualidade para processamento a um custo que seja viável. O objetivo dos produtores rurais é tão relevante que a falta de cumprimento com as obrigações financeiras por parte dos processadores inicia imediatamente um processo de desconfiança e quebra de reputação. A falta de uma real integração entre as partes reside no fato de elas transformarem o que seriam resultados compartilhados e naturais das transações com integração em objetivos individuais. Para que isto ocorra, é preciso que as partes promovam transparência nas transações, o que levaria à construção de boa reputação entre elas e à minimização de ações oportunistas como as observadas.

De modo geral, observou-se que as transações entre produtores rurais e empresas processadoras são superficiais e influenciam diretamente na qualidade e segurança dos VMP ofertados ao consumidor, apesar de ambas as partes terem igualdade de poder nas transações. Os principais entraves que contribuem para que isto ocorra estão descritos no Quadro 3. As suas causas estão inter-relacionadas e dependem da capacidade de integração destes agentes, de forma a diminuir o possível oportunismo entre eles.

Quadro 3. Principais entraves nas transações entre as empresas processadoras e os produtores rurais nos casos estudados.

\begin{tabular}{|c|c|}
\hline Entraves observados & Causas \\
\hline $\begin{array}{l}\text { Falta de comprometimento dos produtores rurais na } \\
\text { continuidade das atividades rurais }\end{array}$ & $\begin{array}{l}\text { Execução de tarefas sem expertise como forma opcional } \\
\text { de obtenção de renda em curto prazo }\end{array}$ \\
\hline Fornecimento irregular de matéria-prima & $\begin{array}{c}\text { Falta de planejamento da empresa processadora junto } \\
\text { aos produtores rurais devido à falta de integração }\end{array}$ \\
\hline $\begin{array}{l}\text { Fornecimento de matéria-prima com qualidade inferior } \\
\qquad \text { à demandada }\end{array}$ & $\begin{array}{l}\text { Falta de assistência técnica eficiente por parte da } \\
\text { empresa processadora como incentivo ao produtor rural } \\
\text { devido à falta de integração }\end{array}$ \\
\hline $\begin{array}{l}\text { Diversificação de clientes pelos produtores rurais, o que } \\
\text { prejudica a qualidade da matéria-prima e o atendimento } \\
\text { às empresas processadoras }\end{array}$ & $\begin{array}{l}\text { Tentativa de diminuir o poder de barganha das empresas } \\
\text { processadoras sobre a produção rural }\end{array}$ \\
\hline \multirow[t]{2}{*}{ Falta de investimentos em tecnologia de campo } & $\begin{array}{l}\text { Insegurança de que os investimentos aumentem o custo } \\
\text { de produção e tornem os produtos pouco competitivos } \\
\text { para outros clientes, aumentando o poder de barganha } \\
\text { das empresas processadoras }\end{array}$ \\
\hline & $\begin{array}{l}\text { Insegurança das empresas processadoras em fornecer } \\
\text { incentivos ao produtor rural sem resultado positivo da } \\
\text { parceria }\end{array}$ \\
\hline $\begin{array}{l}\text { Falta de transparência na fixação de preços de compra de } \\
\text { matérias-primas. }\end{array}$ & $\begin{array}{l}\text { Possível oportunismo das empresas processadoras com } \\
\text { os produtores rurais, já que as cotações das matérias- } \\
\text { primas e as quantidades demandadas ao longo do ano } \\
\text { são de conhecimento mútuo. }\end{array}$ \\
\hline
\end{tabular}

Fonte: Elaborado pelos autores a partir de dados de pesquisa. 


\subsection{A relação processador - transportador}

As transações entre os processadores e os transportadores são diárias e, portanto, de alta frequência o que os faz ter contatos contínuos, inclusive no período de entrega, quando necessário. Esta alta frequência faz com que a possibilidade de ações oportunistas seja minimizada. De fato, de acordo com os entrevistados das empresas processadoras, as relações entre as partes são "amigáveis", mas não as consideram como parcerias, o que é confirmado pelos transportadores. As responsabilidades para a entrega dos produtos são cumpridas sem maiores problemas pelos transportadores, assim como as responsabilidades com o pagamento do frete são cumpridas regularmente pelas empresas processadoras. As relações se resumem ao atendimento mútuo das responsabilidades individuais.

Os principais entraves entre estes agentes e que contribuem para que isto ocorra estão descritos no Quadro 4.

\subsection{A relação processador - distribuidor}

Os distribuidores de VMP nas cadeias estudadas são divididos em dois grandes grupos: varejistas e mercados institucionais. Os varejistas são mercados e supermercados que vendem os VMP nas gôndolas para o consumidor final. Os mercados institucionais são os restaurantes e os VMP são matéria-prima para a preparação de saladas para os seus clientes, que são os comensais. Neste item, o distribuidor será chamado de cliente, já que é a relação que existe entre as empresas processadoras e os mercados varejistas e institucionais. A frequência nas transações com ambos os clientes é alta, o que permite, assim como aos outros agentes, construir confiança e uma boa reputação ao longo do tempo, apesar de haver problemas pontuais nas transações entre as partes no dia a dia. Apesar disto, mantêm contratos formais que estabelecem preço dos produtos, parâmetros de entrega (horários e frequências), valor de logística, descontos financeiros, padrões de qualidade e a obrigatoriedade da presença de promotoras de venda nas lojas, no caso das empresas varejistas. A maioria dos clientes institucionais possui um grau de maturidade maior em relação às empresas varejistas nas questões relacionadas à qualidade dos VMP distribuídos. Os principais entraves entre estes agentes estão descritos no Quadro 5.

A identificação das melhores estruturas de governança entre a empresa processadora e estes agentes contribuem também para minimizar os efeitos negativos sobre as transações e, consequentemente, os entraves para as transações. Para a obtenção destas estruturas de governança, é necessária a análise dos atributos das transações entre os agentes das cadeias de VMP estudadas, conforme a seção seguinte.

\section{Análise dos atributos de transação na cadeia de VMP}

A análise foi conduzida partindo das transações da empresa-foco com os demais agentes da cadeia, ou seja, as transações da empresa processadora com os produtores rurais, com os transportadores e com os mercados varejistas e institucionais. Esta avaliação foi orientada nos fatores reunidos na literatura por Neves (1999) para a análise da especificidade do ativo, atribuindo os níveis ALTO, MÉDIO ou BAIXO aos respectivos atributos de transação. Para promover uma base de análise para as especificidades médias do ativo de cada agente, atribuíram-se valores "1" para "BAIXO", "2" para "MÉDIO” e "3" para "ALTO". A especificidade resultante para cada agente é a média aritmética dos valores estabelecidos nas análises. Como base de análise, consideraram-se os valores de média obtidos na faixa de 1,0 a 1,6 para Baixa especificidade

Quadro 4. Principais entraves nas transações entre as empresas processadoras e os transportadores nos casos estudados.

\begin{tabular}{|c|c|}
\hline Entraves observados & Causas \\
\hline $\begin{array}{c}\text { Inexistência de treinamento aos transportadores nos } \\
\text { requisitos para o transporte dos VMP }\end{array}$ & $\begin{array}{c}\text { Falta de planejamento das empresas processadoras junto } \\
\text { aos transportadores }\end{array}$ \\
\hline $\begin{array}{c}\text { Inexistência de registros formais da temperatura de } \\
\text { transporte e condições de entrega dos VMP aos clientes }\end{array}$ & $\begin{array}{c}\text { Falta de expertise das empresas processadoras em } \\
\text { integrar dados com resultados como evidências de } \\
\text { garantia da qualidade dos VMP entregues. }\end{array}$ \\
\hline $\begin{array}{c}\text { Falta de transparência na identificação de dolo no } \\
\text { transporte de VMP, o que acarreta descontos financeiros } \\
\text { ao transportador }\end{array}$ & $\begin{array}{c}\text { Inexistência de registros formais que evidenciem o dolo } \\
\text { do transportador }\end{array}$ \\
\hline $\begin{array}{c}\text { Dificuldade em gerenciar problemas de entrega e } \\
\text { reclamações de clientes em relação à qualidade dos } \\
\text { produtos }\end{array}$ & $\begin{array}{c}\text { Inexistência de um único responsável pelo transporte de } \\
\text { VMP }\end{array}$ \\
\hline $\begin{array}{c}\text { Falta de investimentos em sistema de frio e seus } \\
\text { controles nos veículos. }\end{array}$ & $\begin{array}{c}\text { Insegurança por parte dos transportadores da } \\
\text { continuidade dos serviços prestados às empresas de } \\
\text { processamento. }\end{array}$ \\
\hline
\end{tabular}

Fonte: Elaborado pelos autores a partir de dados de pesquisa. 
do ativo, 1,7 a 2,3 para Média especificidade do ativo e 2,4 a 3,0 para Alta especificidade do ativo. O Quadro 6 consolida os resultados da análise. As principais contribuições desta seção são a identificação do agente que deve liderar a gestão da qualidade na cadeia e das melhores estruturas de governança entre estes agentes, visando gerenciá-la de modo eficaz e diminuir os custos de transação, respectivamente, o que otimiza a obtenção de produtos finais com qualidade e segurança asseguradas.

\section{Proposta de estruturas de governança entre os agentes da cadeia de VMP}

A análise dos atributos de transação nas cadeias de VMP estudadas permitem algumas observações interessantes. Os resultados mostram que as empresas processadoras possuem ativos de alta especificidade, em detrimento dos demais agentes que possuem ativos de baixa a média especificidade. Esta questão

Quadro 5. Principais entraves nas transações entre as empresas processadoras e os clientes nos casos estudados.

\begin{tabular}{|c|c|}
\hline Entraves observados & Causas \\
\hline $\begin{array}{c}\text { Inexistência de registros formais e integrados entre } \\
\text { empresa processadora e clientes que evidenciem a } \\
\text { temperatura dos vegetais na entrega e as condições } \\
\text { (forma, prazo e horário) dos VMP aos clientes }\end{array}$ & $\begin{array}{c}\text { Falta de planejamento em conjunto entre as empresas } \\
\text { processadoras e os clientes para monitoramento das } \\
\text { condições de entrega do VMP }\end{array}$ \\
\hline $\begin{array}{c}\text { Demora na resposta por parte das empresas } \\
\text { processadoras às demandas dos clientes }\end{array}$ & $\begin{array}{c}\text { Centralização de atividades e informações nas empresas } \\
\text { processadoras e falta de expertise interna para responder } \\
\text { às questões de modo eficiente }\end{array}$ \\
\hline $\begin{array}{c}\text { Entregas dos VMP em valores de } \\
\text { temperatura acima de } 8{ }^{\circ} \mathrm{C}\end{array}$ & $\begin{array}{c}\text { Sub-dimensionamento do compressor de frio do } \\
\text { veículo de transporte para o serviço realizado. Falta de } \\
\text { monitoramento da temperatura durante o transporte para } \\
\text { a realização das entregas }\end{array}$ \\
\hline $\begin{array}{c}\text { Entregas de VMP com itens faltantes ou errados } \\
\text { demandada }\end{array}$ & $\begin{array}{c}\text { As informações são repassadas sem formulários ou } \\
\text { registros, o que permite engano do transportador }\end{array}$ \\
\hline $\begin{array}{c}\text { Entregas de VMP com qualidade aparente inferior à } \\
\text { Utilização de matéria-prima de baixa qualidade; } \\
\text { falta de controle nas funções tecnológicas; falta de } \\
\text { monitoramento da temperatura de transporte }\end{array}$ \\
\hline $\begin{array}{c}\text { Inexistência de proatividade entre as partes para a busca } \\
\text { em conjunto de soluções para os problemas de qualidade } \\
\text { ocorridos. }\end{array}$ & $\begin{array}{c}\text { Falta de senso de parceria entre as partes, fomentado } \\
\text { pela ideia de que a qualidade do produto depende } \\
\text { unicamente da empresa processadora. }\end{array}$ \\
\hline
\end{tabular}

Fonte: Elaborado pelos autores a partir de dados da pesquisa.

Quadro 6. Consolidação da análise dos atributos de transação para os agentes das cadeias de VMP estudadas.

\begin{tabular}{|c|c|c|c|c|c|c|c|c|}
\hline $\begin{array}{c}\text { Atributos de } \\
\text { transação }\end{array}$ & \multicolumn{4}{|c|}{ Caso A } & \multicolumn{5}{c|}{ Caso B } \\
\hline $\begin{array}{c}\text { Especificidade do } \\
\text { ativo }\end{array}$ & $\begin{array}{c}\text { Prod. } \\
\text { Rurais }\end{array}$ & Proc. & Transp. & Clientes & $\begin{array}{c}\text { Prod. } \\
\text { Rurais }\end{array}$ & Proc. & Transp. & Clientes \\
\hline Físico & 1 & 3 & 1 & 1 & 1 & 3 & 2 & 1 \\
\hline $\begin{array}{c}\text { Recursos } \\
\text { Humanos }\end{array}$ & 1 & 3 & 1 & 1 & 1 & 3 & 1 & 2 \\
\hline Ativo dedicado & 1 & 2 & 1 & 1 & 1 & 2 & 1 & $1(3 *)$ \\
\hline Marca & 1 & 3 & 1 & 1 & 1 & 2 & 1 & 1 \\
\hline Locacional & 1 & 1 & 1 & 1 & 1 & 2 & 1 & 2 \\
\hline Temporal & 2 & 3 & 3 & 3 & 2 & 3 & 3 & 3 \\
\hline $\begin{array}{c}\text { Especificidade } \\
\text { média do ativo }\end{array}$ & 1,2 & 2,5 & 1,1 & 1,1 & 1,2 & 2,5 & 1,5 & $1,7(2 *)$ \\
\hline $\begin{array}{c}\text { Classificação das } \\
\text { especificidades } \\
\text { do ativo }\end{array}$ & Baixa & Alta & Baixa & Baixa & Baixa & Alta & Baixa & Média \\
\hline Frequência & Alta & n.a. & Alta & Alta & Alta & n.a. & Alta & Alta \\
\hline Incerteza & Média & n.a. & Baixa & Baixa & Alta & n.a. & Baixa & Baixa \\
\hline
\end{tabular}

*Um dos clientes realizou grandes investimentos na empresa processadora, o que faz aumentar o nível de especificidade de ativos e, consequentemente, a sua classificação geral na especificidade média dos ativos. n.a. = não se aplica. Fonte: Elaborado pelos autores. 
coloca a empresa em uma situação de dependência entre os demais agentes na produção de produtos com qualidade assegurada. De fato, esta situação de "dependência" explica a necessidade das empresas processadoras em monitorar todos os processos para que seja garantida a obtenção de um produto final com qualidade assegurada e, consequentemente, se tornar o agente gestor da qualidade na cadeia de VMP, desenhando a estrutura de controle das transações observada nos casos estudados.

A recorrência nas relações forma reputação entre os agentes, conforme observado por Farina et al. (1997) e Azevedo e Faulin (2003). Deste modo, a alta frequência nas relações permitiu a seleção destes agentes e novas formas de integração, conforme relatado anteriormente, de forma a resultar em uma relação ganha-ganha para todos. Observa-se nos casos estudados uma diferença de incertezas nas relações entre os produtores rurais e a empresa processadora, variando de um nível médio para alto, conforme a análise efetuada e mostrada na Figura 1.

As demais relações entre as empresas processadoras, os transportadores e mercados varejista e institucional são caracterizadas por uma baixa incerteza. Verifica-se uma alta dependência das empresas processadoras pela matéria-prima com qualidade (atributos sensoriais e disponibilidade contínua) para o processamento mínimo. Apesar de esta qualidade ser exigida, observa-se a possibilidade de não atendimento aos requisitos necessários, esclarecidos em acordos pré-transações. A grande assimetria de informações entre os produtores rurais e as empresas processadoras gera incertezas, incompletude de contratos e finalmente o risco moral, pois o custo de monitoramento do cumprimento dos contratos é impraticável, conforme estabelecido por Williamson (1985) e observado por Machado (2000), Spers (2003) e Pitelli (2004) para as cadeias agroindustriais.

Estas observações levam à necessidade de se avaliar os custos de transação entre estes agentes e de se identificar as melhores formas para reduzi-los. Conforme Azevedo (2000) e Spers (2003), as formas de governança dos contratos são as estruturas que minimizam os efeitos destas incertezas e diminuem os custos de transação.

De acordo com o Quadro 2 e com as análises das especificidades dos ativos e da incerteza realizadas nos casos estudados, pode-se definir a melhor forma

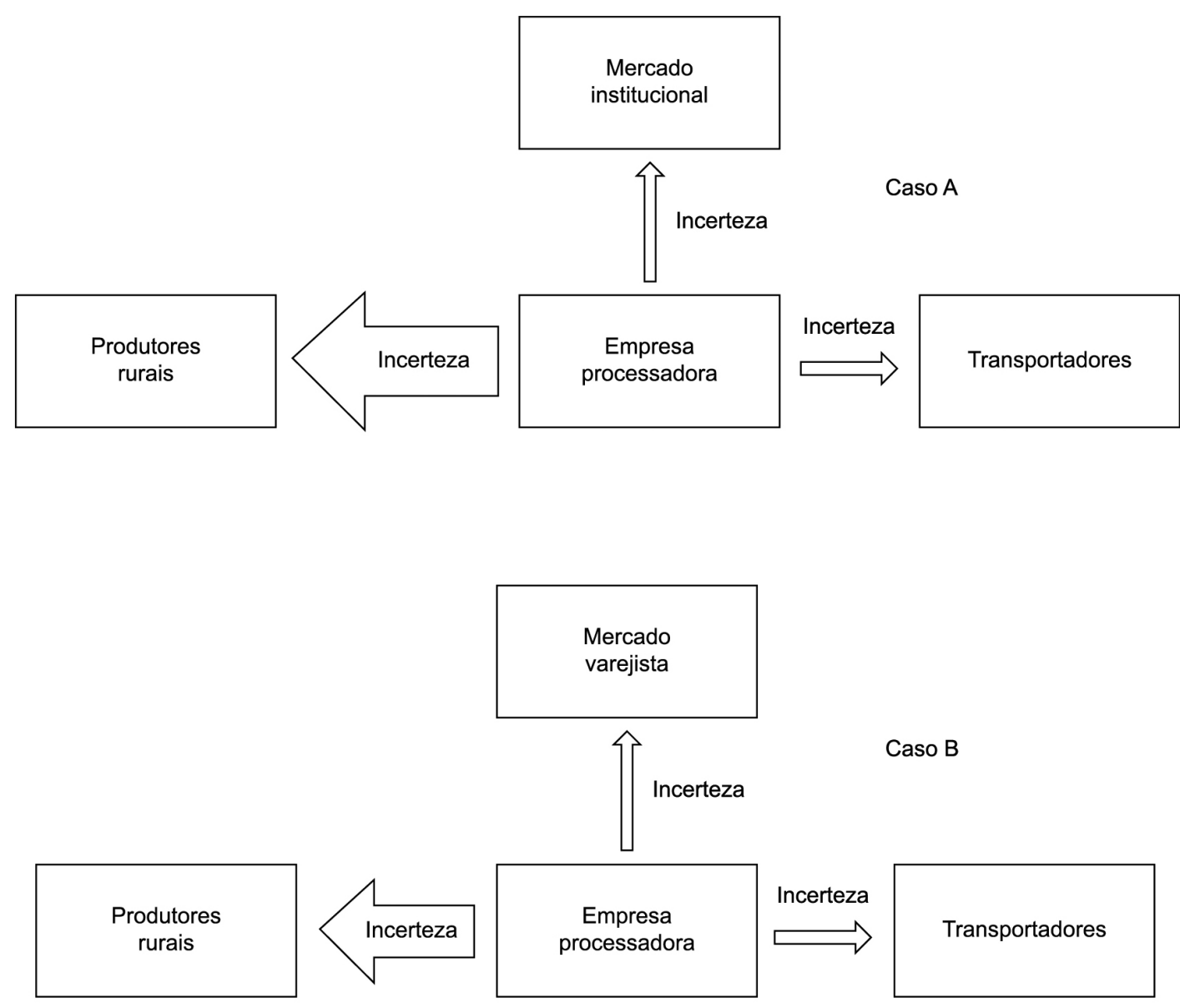

Figura 1. A incerteza entre os agentes nas cadeias de VMP estudadas. Fonte: Elaborada pelos autores. 
de governança entre a empresa processadoras de VMP, os produtores rurais, os transportadores e os mercados varejista e institucional, conforme mostra a Figura 2.

As estruturas de governança propostas para a cadeia de VMP são do tipo híbrida e verticalizada (hierárquica). Conforme Williamson (1996), as estruturas híbridas são regidas por acordos (contratos informais) e contratos formais. Faulin e Azevedo (2003) complementam as parcerias como formas de estruturas híbridas. Verifica-se que o fornecimento de matéria-prima é o fator mais crítico nas transações da cadeia de VMP. Por este motivo, torna-se o condicionador dos dois tipos de governança na cadeia. Os parágrafos seguintes justificam as formas de governança propostas.

\subsection{Estrutura de governança híbrida}

Os acordos (contratos informais) são a forma encontrada pelo produtor rural e pela empresa processadora para governar as transações entre eles, quando as matérias-primas necessárias não sao estratégicas para a empresa processadora. Dada a alta especificidade de ativos da empresa processadora, os contratos formais seriam a opção mais acertada para as transações, pois estabeleceria formas e prazos de pagamento e remuneração, prazos de entrega, requisitos de qualidade e disponiblidade no fornecimento de matéria-prima. Entretanto, os produtores rurais não aceitam formalizar contratos. Entendem que não poderiam arcar com a responsabilidade de fornecimento em caso de intempéries que afetem a produção agrícola, ou de condições climáticas que impactem a qualidade dos produtos agrícolas ou no caso de uma alta de preços de insumos que impactaria o custo da produção agrícola, inviabilizando o fornecimento de matérias-primas, já que estariam com os preços contratados. Ainda que os preços estabelecidos para as transações com a matériasprimas estivessem de acordo com a sua variação no mercado, a imprevisibilidade das condições climáticas influencia bastante o desinteresse na formalização de acordos comerciais por parte desses fornecedores. As empresas processadoras entendem que a grande frequência nas transações formam reputação entre as partes e o desacordo entre as partes é improvável ou, se acontecer, não aumenta siginificativamente os custos de transação para a empresa processadora. Ainda que tivessem contratos, entendem que o ropimento não resolveria o problema da necessidade imediata de ter disponível a matéria-prima para processamento. Ou seja, independente da formalização ou não dos contratos, o rompimento gera as mesmas consequências, acarretando as mesmas formas para a procura de alternativas, não interferindo em maior ou menor custo de transação. As empresas processadoras alegam que, como as matérias-primas não são estratégicas, podem substituir o fornecimento, que é normalmente em pequenas quantidades de matériasprimas, com outros produtores, ou indisponibilizar, pontualmente, os VMP que as contêm ao cliente. De

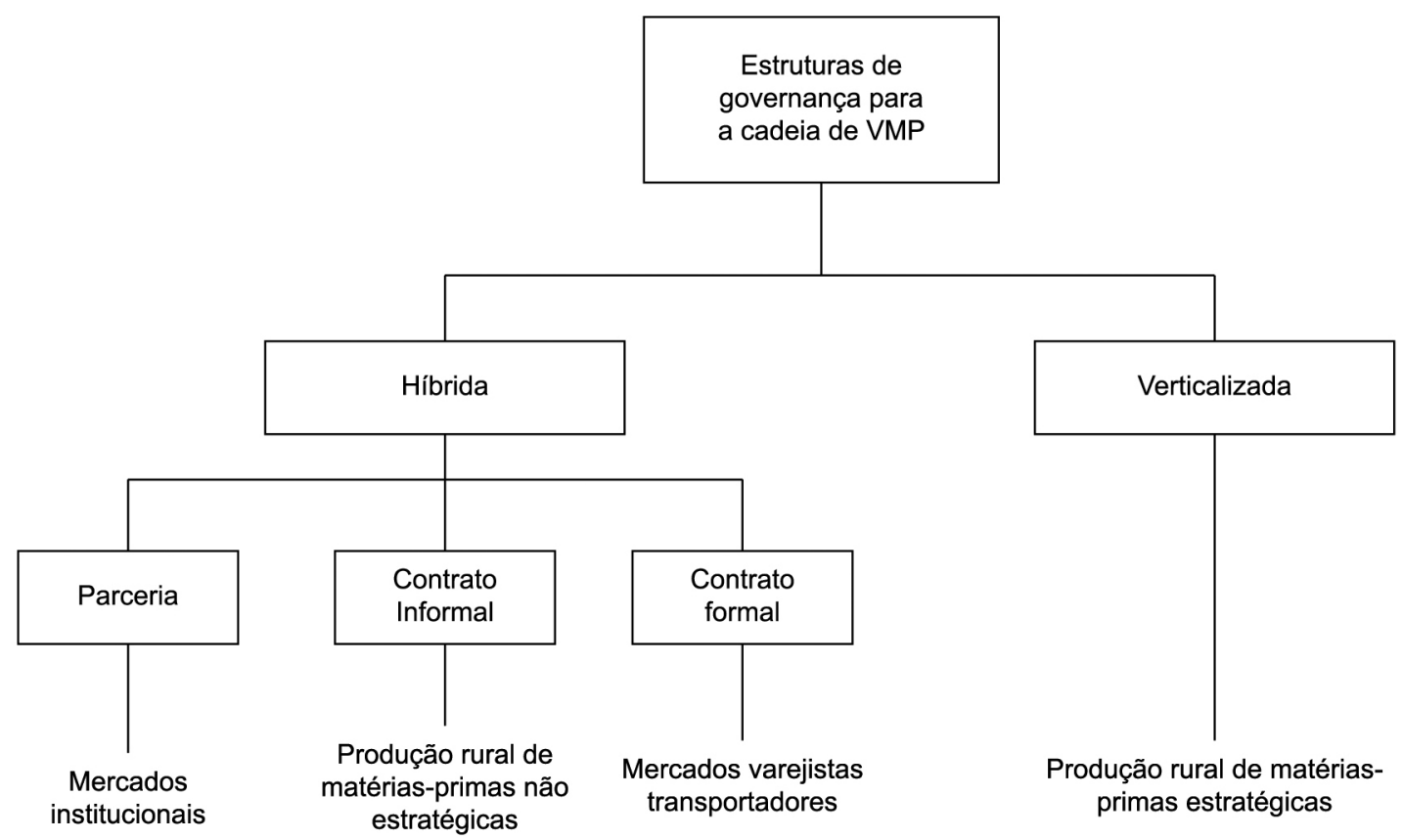

Figura 2. Estruturas de governança propostas para a cadeia de VMP. Fonte: Elaborado pelos autores, baseado em Faulin e Azevedo (2003). 
fato, foi constastado que há a possibilidade de falta de fornecimento de matérias-primas e, nestes casos, é realizada a procura por alternativas com outros produtores, inclusive com a participação dos produtores que não tiveram condições de fornecimento. As partes entendem que possíveis rompimentos de acordos não são causados por ações oportunistas e sim pela real impossibilidade de fornecimento ou aquisição.

Os contratos formais são a forma encontrada entre as partes para reduzir os custos de transação, principalmente aqueles realcionados ao custo de monitoramento dessas transações. Nos mercados varejistas, os itens contratados dizem respeito principalmente aos prazos de entrega dos produtos finais, as formas e prazo de pagamento pelos produtos entregues e o desconto financeiro para as quebras existentes. Este último item é interessante para ambas as partes. Por serem produtos perecíveis, sempre existem perdas, o que se chama entre estes agentes de "quebras". Como as quebras podem ser causadas por ações oportunistas nos mercados varejistas (manipulação inadequada, exposição para venda em temperatura abaixo da de refrigeração, falta de atenção ao sistema primeiro que vence é o primeiro que sai), a fixação do valor fixo de desconto, promove maior atenção do mercado no controle das atividades que impactam na qualidade do produto, no intuito de se evitar quebras superiores a estes níveis. Esta atenção é voltada inclusive na avaliação da qualidade aparente do produto recebido pelo mercado, motivando a empresa processadora a produzir produtos com qualidade assegurada. O possível oportunismo por parte das empresas processadoras em aumentar o preço dos produtos no percentual de quebra que é descontado é minimizado, considerando o maior poder de barganha do mercado varejista e a presença de concorrentes.

No caso dos transportadores, os contratos formais visam estabelecer as condições de transporte de produtos, prazos para entrega e formas de remuneração pelo serviço prestado. Tais contratos responsabilizam financeiramente os transportadores pelas perdas de produtos comprovadamente por dolo do transportador. Como a comprovação é uma forma de evidenciar o dolo, a empresa processadora arca com um custo de transação adicional que é o custo de monitoramento das condições do transporte e dos produtos durante o transporte. Como entre os outros agentes da cadeia, a alta frequência nas transações seleciona os transportadores e minimiza ações oportunistas de ambos por meio da construção da reputação entre eles.

As transações entre as empresas processadoras e o mercado institucional por meio da parceria, a terceira forma de estrutura híbrida de governança proposta, são efetuadas em um ambiente de dependência mútua, em função de suas especificidades de ativos variarem entre médio e alto. A parceria surge da necessidade do mercado institucional estar muito exposto a problemas de qualidade nos vegetais que podem ser identificados pela tendência de parceria entre as empresas processadoras e o mercado institucional, devido às cresecentes cobranças por qualidade e rastreabilidade do alimento pelo consumidor, conforme Machado (2000). Estas parcerias dizem respeito à alocação de recursos financeiros, materiais e humanos para a verticalização da produção rural e no transporte dos produtos aos mercados, permeados por contratos formais, a fim de garantir os investimentos efetuados e a exclusividade de fornecimento.

\subsection{Estrutura de governança verticalizada}

Em meio às várias formas de governança híbrida, surge a necessidade de definir uma forma de transação entre a empresa processadora e a produção rural, diferentemente daquela definida na estrutura de governança híbrida, gerida por acordos informais, conforme estabelecido anteriormente. Esta necessidade é justificada pela grande dependência das empresas processadoras pelas matérias-primas, chamadas de estratégicas para as empresas processadoras, pela alta incerteza nas transações, pela alta assimetria de informações entre produtores rurais e empresas processadoras e pela incapacidade de monitoramento dos atributos de qualidade da matéria-prima, necessários para o processamento mínimo. Estas questões levam à incompletude de contratos e ao aumento dos custos de transação, principalmente daqueles relacionados ao monitoramento (avaliação e observação) da qualidade da matéria-prima, conforme verificado por Barzel (1997), Azevedo (2000) e Mallmann (2000). As matérias-primas estratégicas são aquelas responsáveis por grande parte da composição do portfólio de produtos finais e, portanto, pelo faturamento das empresas processadoras. Assim, mesmo que houvesse completude de contratos nas transações entre produtores rurais e processadores e que os produtores rurais concordassem em formalizar o fornecimento, a sua ruptura pelos produtores rurais, por oportunismo ou não, causaria consequências negativas em termos financeiros e na imagem da empresa processadora no mercado. Isto se deve à sua incapacidade de responder, alternativa e imediatamente, à esta ruptura na busca de matériasprimas com a qualidade e na quantidade necessárias para processamento.

A aquisição de matérias-primas com qualidade garantida é de difícil mensuração, uma vez que esta garantia somente é alcançada por meio de monitoramento de todos os atributos que compõem a qualidade desejada (BARZEL, 1997). Os custos envolvidos na transação de aquisição das matériasprimas seriam muito altos e a transação cercada de muitas incertezas. Deste modo, a hierarquização 
da produção rural destas matérias-primas pelas empresas processadoras se tornam a única alternativa para os objetivos da cadeia (ou, pelo menos, para os objetivos da empresa processadora e seus clientes). De fato, Powell (1990) mostra que a estrutura de governança por hierarquia é adequada para transações que envolvam incerteza, ocorrem com frequência e requerem investimentos específicos para as transações, como é o caso aqui identificado e detalhadamente descrito na seção anterior.

\section{Conclusões/Considerações finais}

$\mathrm{O}$ resultado das transações entre os agentes da cadeia de VMP permite verificar que a empresa processadora lidera a gestão da qualidade na cadeia. Como foi verificado, os clientes exigem os produtos com as características da qualidade (qualidade aparente, segurança, prazo de entrega, quantidade e disponibilidade contínua) necessárias para a distribuição aos consumidores finais. Apesar de os contratos entre estas partes definirem basicamente os prazos para a entrega e as condições financeiras, está implícito que o produto deve atender às características da qualidade. Neste sentido, a empresa processadora precisa mostrar e evidenciar que seus produtos atendem a estas expectativas. Kirmani e Rao (2000) definem estas evidências como sinais da qualidade que, segundo Machado (2002), são necessários para convencer o comprador de que os produtos atendem às suas exigências e, consequentemente, diminuir a assimetria de informações entre estes agentes que transacionam. Estas questões motivam o comprador a pagar o produto pela sua qualidade e minimiza a possibilidade de seleção adversa. A seleção adversa ocorre quando o comprador não consegue avaliar os requisitos da qualidade de um produto e o pagamento é estabelecido em função de um produto de qualidade mínima (AKERLOF, 1970).

A introdução e implantação das formas de governança propostas possibilitam e facilitam à empresa processadora reunir as evidências. Entretanto, por si só, estas formas de contratação não são suficientes para demonstrar tais evidências para o mercado comprador. Estas deverão ser formadas por meio de um sistema de gestão da qualidade e segurança dos vegetais minimamente processados. As estruturas de governança propostas facilitam a implantação do sistema de gestão e viabilizam o seu funcionamento. Do outro lado da cadeia, os mercados varejistas e institucionais devem valorizar os produtos com qualidade e segurança garantidas e evidenciadas, como forma de incentivar a manutenção e a melhoria da qualidade e da segurança dos vegetais minimamente processados.

Este trabalho corrobora outras pesquisas (STRYDOM, 2010; TRU et al., 2012; NUINTIN et al., 2012) que concluem a necessidade de estruturas de governança para minimizar os custos de transação no processamento agroindustrial e, de certa forma, responde e contribui para o encaminhamento de alguns dos desafios elencados, principalmente a resposta das pequenas empresas processadoras de alimentos no que tange aos padrões de qualidade, à disponibilidade de matérias-primas e às formas de alianças entre os agentes de uma cadeia.

Esta pesquisa relaciona a teoria de custos de transação à teoria da gestão da qualidade, uma vez que, mais do que caracterizar, propõe, de forma inédita, formas de coordenação (estruturas de governança) na cadeia de processamento mínimo de vegetais, a partir de um estudo aprofundado das transações e suas características específicas entre os agentes da cadeia. As propostas destas estruturas de governança têm por objetivo minimizar a ocorrência de risco moral entre o agentes que transacionam e possibilitar a evidenciação, ao longo da cadeia, dos sinais de qualidade, que são a certificação da qualidade ou os registros para rastreabilidade para os produtos finais. A certificação e, consequentemente, a rastreabilidade dos produtos finais somente são alcançadas se a cadeia tiver a capacidade de garantir a qualidade do alimento em todas as suas fases (BERTOLINO, 2010; LUNING; MARCELIS, 2009), seja como matéria-prima, seja como produto final na empresa processadora, seja como produto sendo transportado ou seja como produto disponível no mercado distribuidor (institucional ou varejo).

Para a cadeia, este estudo contribui para que o agente coordenador, e os outros agentes, repensem suas formas de relacionamento e atividades e responsabilidades que devem desempenhar e exercer, para que transformem os conflitos internos em relacionamentos colaborativos, sólidos e duradouros. Sem dúvida, a TEC pode subsidiar um estudo aprofundado na implantação destas formas de governança por meio das suas características básicas das transações e dos seus pressupostos comportamentais observados. Sob a complementariedade da TEC sobre a TCT, existe a hipótese de que a estrutura verticalizada proposta neste trabalho pode se transformar em uma estrutura híbrida com garantias fortes, já que existe um risco, embora pequeno, de risco moral por parte da empresa processadora com consequências diretas para a qualidade e/ou a segurança do vegetal processado.

\section{Referências}

AKERLOF, G. A. The Market for "Lemons": Quality Uncertainty and the Market Mechanism. Quarterly Journal of Economics, v. 84, n. 3, 1970, p. 488-500. http://dx.doi.org/10.2307/1879431

ARROW, K. J. Uncertainty and the Welfare Economics of Medical Care. American Economic Review, v. 53, 1963, p. $941-973$ 
AZEVEDO, P. F. Nova economia institucional: referencial geral e aplicações para a agricultura. Agricultura em São Paulo, v. 47, n. 1, p. 33-52, 2000.

AZEVEDO, P. F.; FAULIN, E. J. Subsistemas Estritamente Coordenados Baseados em Confiança: O Caso de Verduras. In: INTERNACIONAL DE ECONOMIA E GESTÃO DE NEGÓCIOS AGROALIMENTARES, 4., 2003, Ribeirão Preto. Anais... Ribeirão Preto: FEARP/USP, 2003.

BARZEL, Y. Economic analysis of property right. 2nd ed. Cambridge University Press, 1997. http://dx.doi. org/10.1017/CBO9780511609398

BARZEL, Y. Standards and the form of agreement. Economic Inquiry, v. 42, p. 1-13, 2004. http://dx.doi. org/10.1093/ei/cbh040

BERTOLINO, M. T. Gerenciamento da qualidade na indústria alimentícia. Ênfase na segurança dos alimentos. Porto Alegre: Artmed, 2010. 320 p.

BREITENBACH, R. Estruturas de mercado da fatores e governança na cadeia produtiva de leite: um estudo de caso do município de Ajuricaba-RS. 2008. Dissertação (Mestrado em Extensão Rural)-Univerdidade Federal de Santa Maria, Santa Maria, 2008.

COASE, R. H. The nature of firm. Economica, New Series, v. 4, n. 16, p. 386-405, 1937. http://dx.doi. org/10.1111/j.1468-0335.1937.tb00002.x

CORDEIRO, K. W.; TREDEZINI, C. A. O.; CARVALHO, C. M. Análise da produção de hortaliças sob a ótica da economia dos custos de transação, na cidade de campo Grande-MS. In: CONGRESSO BRASILEIRO DE ECONOMIA E SOCIOLOGIA RURAL, 46., 2008, Rio Branco. Anais... Rio Branco, 2008.

COSTA, D. R. M.; BIALOSKORSKI NETO, S. Rating de Cooperativas Agropecuárias: uma contribuição metodológica. Revista de Economia e Agronegócio, v. 3, n. 4, p. 509-536, 2005.

FARINA, E. M. et al. A experiência de regulamentação de sistemas agroindustriais no Brasil. In: FARINA, E. M. et al. Competitividade: Mercado, Estado e Organizações. Piracicaba: Ed. Singular, Fapesp/ Pensa, 1997. p. 207-214.

FAULIN, E. J.; AZEVEDO, P. F. Distribuição de hortaliças na agricultura familiar: uma análise das transações. Informações Econômicas, v. 33, n. 11, p. 24-37, 2003.

JENSEN, M. C.; MECKLING, W. H. Theory of the Firm: Managerial Behavior, Agency Costs and Ownership Structure. Journal of Financial Economics, v. 3, n. 4, p. 305-360, 1976. http://dx.doi. org/10.1016/0304-405X(76)90026-X

KIRMANI, A.; RAO, A. R. No pain, no gain: a critical review of the literature on signaling unobservable product quality. Journal of Marketing, v. 64, p. 66-79, 2000. http://dx.doi.org/10.1509/jmkg.64.2.66.18000

LEME, P. H. M. V. Os Pilares da Qualidade: o processo de implementação do Programa de Qualidade do Café (PQC) no mercado de café torrado e moído do Brasil. 2007. 110 f. Dissertação (Mestrado em Administração)Universidade Federal de Lavras, Lavras, 2007.

LUCCI, C. R.; SCARE, R. F.Custos de transação no ambiente portuário: uma aplicação da nova economia institucional para o porto de Santos. In: SEMINÁRIOS
EM ADMINISTRAÇÃO, 7., 2004, São Paulo. Anais... São Paulo: FEA/USP, 2004.

LUNING, P. A.; MARCELIS, W. J. A food quality management research methodology integrating technological and managerial theories. Trends in Food Science \& Technology, v. 20, p. 35-44, 2009. http://dx.doi.org/10.1016/j.tifs.2008.09.013

MACHADO, E. L. O papel da reputação na coordenação vertical da cadeia produtiva de frutas, legumes e verduras frescas. 2000. Tese (Doutorado em Administração)-Faculdade de Economia, Administração e Contabilidade, Universidade de São Paulo, 2000.

MACHADO, R. T. M. Rastreabilidade, tecnologia da informação e coordenação de sistemas agroindustriais. 2002. Tese (Doutorado em Economia)Faculdade de Economia, Administração e Contabilidade, Universidade de São Paulo, 2002.

MALLMANN, D. O. Análise das políticas de suprimento praticadas pelas grandes empresas industriais brasileiras. 2000. 294 f. Tese (Doutorado em Administração)-Universidade Federal do Rio Grande do Sul, Porto Alegre, 2000.

NANTES, J. F. D.; LEONELLI, F. C. V. A estruturação da cadeia produtiva de vegetais minimamente processados. Revista FAE, v. 3, n. 3, p. 61-69, set./dez. 2003.

NEVES, M. F. Um modelo para planejamento de canais de distribuição no setor de alimentos. 1999. $187 \mathrm{f}$. Dissertação (doutorado em Administração)-Faculdade de Economia, Administração e Contabilidade, Universidade de São Paulo, 1997.

NUINTIN, A. A.; CURI, M. A.; SANTOD, A. C. Caracterização e análise das transações resultantes da contratação de mão de obra na atividade cafeeira sob a ótica da Economia dos Custos de Transação. Custos \& agronegócio, v. 8, n. 3, 2012.

PITELLI, M. M. Sistema agroindustrial brasileiro da carne bovina: análise do impacto das mudanças institucionais europeias sobre as estruturas de governança. 2004. Dissertação (Mestrado em Ciências)-Escola Superior de Agricultura Luiz de Queiroz, Universidade de São Paulo, Piracicaba, 2004.

POWELL, W. W. Neither market nor hierarchy: network forms of organization. Research in Organizational Behavior, v. 12, p. 295-336, 1990.

SPERS, E. E. Mecanismos da regulação da qualidade e segurança em alimentos. 2003. $136 \mathrm{f}$. Tese (Doutorado em Administração)-Faculdade de Economia e Administração, Universidade de São Paulo, São Paulo, 2003.

SPROESSER, R. L.; ROSINA, L.; VILPOUX, O. F. Complementaridades da economia dos custos de transação e da teoria econômica das convenções: um estudo de caso do sistema agroindustrial do mel de campo Grande-MS. Organizações Rurais e Agroindustriais, v. 12, n. 2, 2010.

STRYDOM, D. B. et al. Reduction of transaction cost within the South African potato processing industry. African Journal of Agriculture Research, v. 7, n. 47, 2012.

TRU, N. A. et al. Linkages in production and distribution of exported vegetables: perspectives of farmers and firms in Luc Nam district, Bac Giang province, 
Vietnam. Journal of the International Society for Southeast Asian Agricultural Sciences, v. 18, n. 1, 2012.

VILPOUX, O. Desempenho dos arranjos institucionais e minimização dos custos de transação: transações entre produtores e fecularias de mandioca. Revista de Economia e Sociologia Rural, v. 49, n. 2, 2011. http://dx.doi.org/10.1590/S0103-20032011000200001 WILLIAMSON, O. E. The Economic Institutions of Capitalism: Firms, Markets and Relational Contracts. New York: The Free Press, 1985. 450 p.

WILLIAMSON, O. E. La Instituciones Económicas del Capitalismo. Tradução de Eduardo L. Suarez. México: Fondo de Cultura Económica, 1989.
WILLIAMSON, O. E. The mechanisms of governance. New York: Oxford University Press, 1996. 429 p.

YIN, R. K. Estudo de caso - planejamento e métodos. 3. ed. Porto Alegre: Bookman, 2007.

ZYLBERSZTAJN, D. Estruturas de governança e coordenação do agrobusiness. 1995. Tese (Livre docência)-Faculdade de Economia, Administração e Contabilidade, Universidade de São Paulo, São Paulo, 1995.

ZYLBERSZTAJN, D.; FARINA, E. M. M. Q. Strictly Coordinated Food-Systems: Exploring the Limits of Coasian Firm. International Food And Agribusiness Management Review, v. 2, n. 2, p. 249-265, 1999. http://dx.doi.org/10.1016/S1096-7508(00)00014-8 